\title{
Cohort profile: why do people keep hurting their back?
}

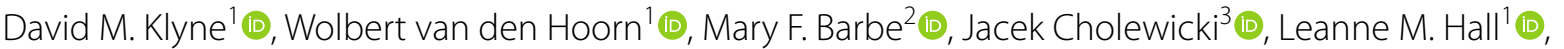

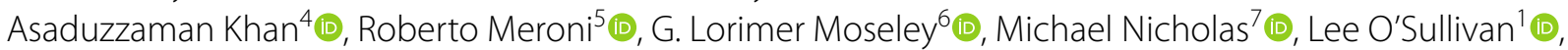

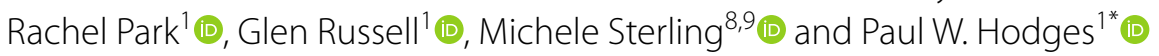

\begin{abstract}
Objective: Low back pain (LBP) is one of the most disabling and costly conditions worldwide. It remains unclear why many individuals experience persistent and recurrent symptoms after an acute episode whereas others do not. A longitudinal cohort study was established to address this problem. We aimed to; (1) evaluate whether promising and potentially modifiable biological, psychological, social and behavioural factors, along with their possible interactions, predict LBP outcome after an acute episode; (2) compare these factors between individuals with and without acute LBP; and (3) evaluate the time-course of changes in these factors from LBP onset. This paper outlines the methodology and compares baseline characteristics between acute LBP and control, and LBP participants with and without follow-up.
\end{abstract}

Results: 133 individuals with acute LBP and 74 pain-free individuals participated. Bio-psycho-social and behavioural measures were collected at baseline and 3-monthly for 12 months (LBP) or 3 months (control). Pain and disability were recorded fortnightly. Baseline characteristics were mostly similar between those who did and did not return for follow-up. Initial analyses of this cohort have revealed important insights into the pathways involved in acute-tochronic LBP. These and future findings will provide new targets for treatment and prevention of persistent and recurrent LBP.

Keywords: Low back pain (LBP), Acute to chronic, Biological factors, Psychological factors, Social factors, Behavioural factors

\section{Introduction}

Low back pain (LBP) is the world's leading cause of disability [1] and is associated with enormous and escalating costs to society [2]. Most of this burden is attributed to the condition when LBP becomes persistent or recurrent. Why some individuals with acute LBP recover, whereas others do not [3, 4], is largely unknown.

\footnotetext{
*Correspondence: p.hodges@uq.edu.au

${ }^{1}$ NHMRC Centre of Clinical Research Excellence in Spinal Pain, Injury and Health, School of Health and Rehabilitation Sciences, The University of Queensland, Brisbane, QLD 4072, Australia

Full list of author information is available at the end of the article
}

Although psychosocial factors have generally been considered stronger predictors of long-term outcome than diagnostic or injury-related factors $[5,6]$, they only explain a small proportion of the variance in outcome $[6,7]$. Biological factors have largely been dismissed and the few that have been comprehensively addressed (e.g., muscle strength/endurance [8]) have little relation to outcome [9]. With this incomplete understanding of factors related to LBP outcome, it is not surprising that most treatments have modest effects at best [10] and are generally unable to prevent recurrence/persistence of pain [11].

We argue that three issues underlie a fresh approach to this problem. First, novel biological factors that could 
plausibly contribute to LBP outcome have been identified in cross-sectional studies, e.g., systemic inflammation, trunk muscle morphology/function, and processing of pain. Up until now, these potentially modifiable factors had not been tested longitudinally from the initial onset of symptoms, and analyses of the early time-points from the cohort presented in this paper are providing promising results [12-14]. Second, although interaction between biological, psychological and social factors is implied in the biopsychosocial model of pain, this interaction has received little attention in past longitudinal studies of LBP outcome. Again, early analyses from the present cohort have revealed interaction between features such as depression, cytokines and poor LBP outcome [12-16]. Third, there is growing evidence that behavioural factors such as sleep interact with the "biopsychosocial" components of LBP, but their contribution to outcome is unknown. This too has been supported by early observations [12, 14]. Further, little is known of the time course of changes in each of the biopsychosocial domains over 12 months following an acute LBP episode. There is strong foundation to evaluate whether candidate biological factors, along with their possible interaction with psychosocial factors, contribute to the transition from acute LBP to that of persistent/recurrent symptoms.

The purpose of this paper is to provide a profile of a cohort study that aims to; (1) evaluate whether outcome after an acute episode of LBP can be predicted by the most promising bio-psycho-social factors and/or the interactions between them; (2) compare these factors between individuals with and without acute LBP; and (3) evaluate the time course of changes in these factors following LBP onset. This paper outlines the participants, measures and data collection schedule, and compares baseline characteristics between acute LBP and control, and follow-up and non-follow-up LBP participants.

\section{Main text \\ Methods \\ Study design}

This longitudinal cohort study involved measures of variables within the biological, psychological and social domains (Table 1) at multiple time-points for 12 months (Additional file 1: Table S1). Measures of sleep, physical activity, alcohol consumption and smoking were grouped separately in a "behavioural" domain as they cross between classical domains. Eligible participants completed a series of detailed online questionnaires related to their pain and disability level, health, demographics, behaviour, and psychosocial status within $24 \mathrm{~h}$ of undertaking a laboratory-based session $(\sim 4 \mathrm{~h})$ at the University of Queensland to assess biological variables. Measures (laboratory-based biological measures and online questionnaires) were repeated at 3, 6 and 9 months for LBP participants, and at 3 months for control participants. At 12 months, questionnaires were completed by all participants in the LBP group in addition to a separate 12-month recall questionnaire relating to the trajectory of their LBP since initial assessment for the study. Participants were also instructed (and reminded) via email to report their pain and disability level every fortnight for 3 (controls) or 12 months (LBP) via an online survey. For some analyses that have been conducted to date, these pain and disability data have been used to classify LBP participants as either "unrecovered", "partially recovered" or "recovered" at follow-up (for details see Additional file 1: Table S2).

\section{Participant recruitment}

A total of 1849 individuals from Brisbane (and surrounds), Australia, were screened between April 2012 and September 2017 (Fig. 1). Participants were recruited through advertisements around the University campus and local community, social media, three nearby hospitals and via a professional recruitment agency (Trialfacts).

Screening was conducted using two different methods. Initially, eligibility was determined via email and/ or phone, and when this method was used the reason(s) for exclusion at this initial screening were not recorded. This was replaced with an automated online screening questionnaire from April 2014, with reasons for exclusion recorded. The inclusion and exclusion criteria for LBP participants are outlined in Additional file 1: Table S3. Participants did not need to be experiencing their first ever LBP episode. Previous LBP was recorded for inclusion as a covariate. Control participants were included if they had not experienced LBP within the last month in addition to meeting the exclusion criteria in Additional file 1: Table S3.

At the first laboratory testing session (after initial screening), eligibility for inclusion were confirmed using data from the baseline questionnaire (completed within $24 \mathrm{~h}$ of the first laboratory-based session), to ensure that the participant's average level of pain and LBPrelated disability in the past week exceeded the inclusion threshold ( $\geq 1 / 10$ for pain; $\geq 1 / 24$ for disability). Potential control participants who reported a score $>0$ on a 0 ("no pain") to 10 ("worst pain imaginable") numerical rating scale (NRS) and/or the Roland Morris Disability Questionnaire (RMDQ [35], [for definition of measures see Table 1]), or provided no scores were excluded from the study $(\mathrm{N}=14)$. Potential LBP participants who reported $<1$ on the pain NRS and/or the RMDQ, or provided no scores in the past week were excluded from the study $(\mathrm{N}=8)$. After data collection, criteria for exclusion 


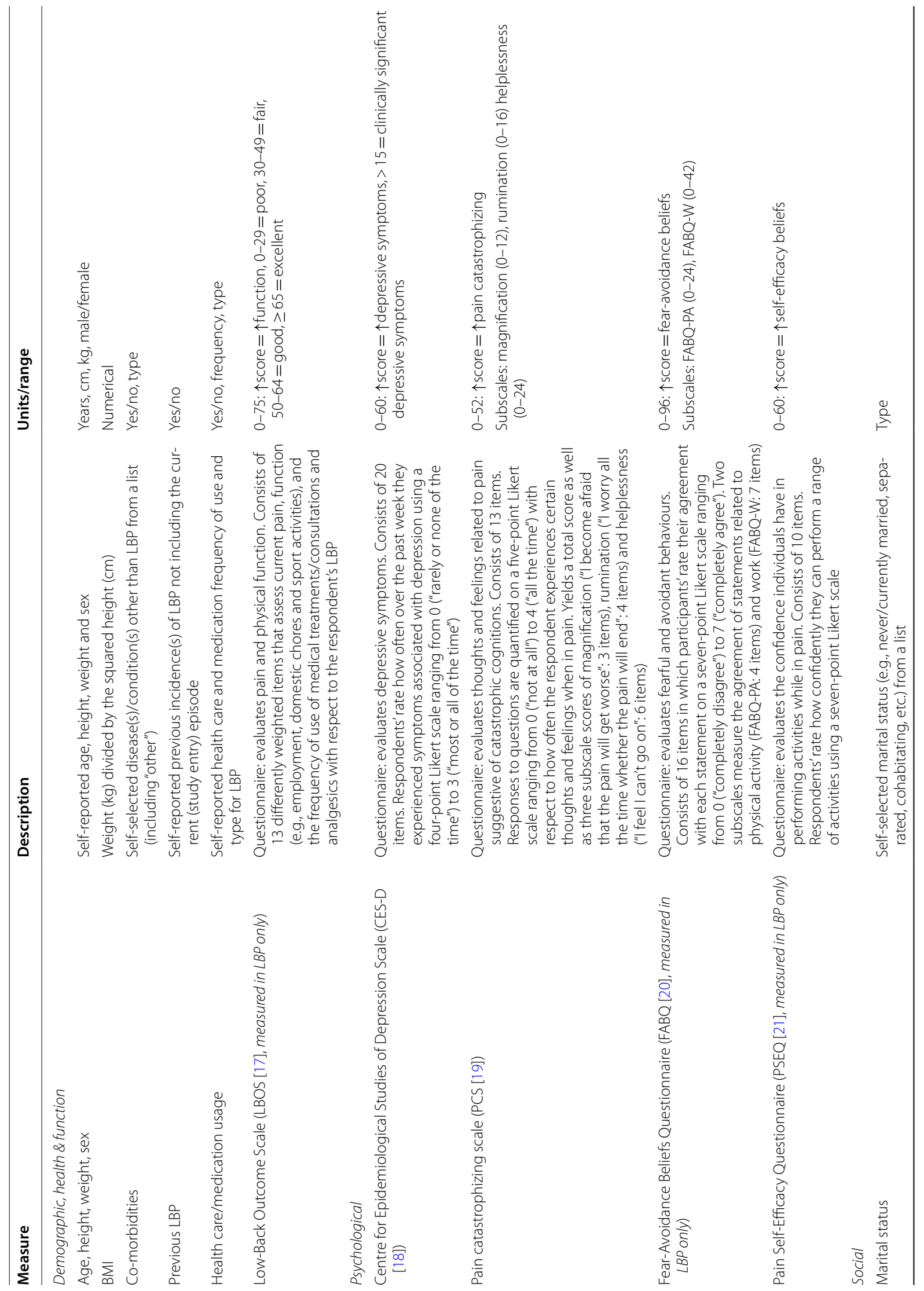




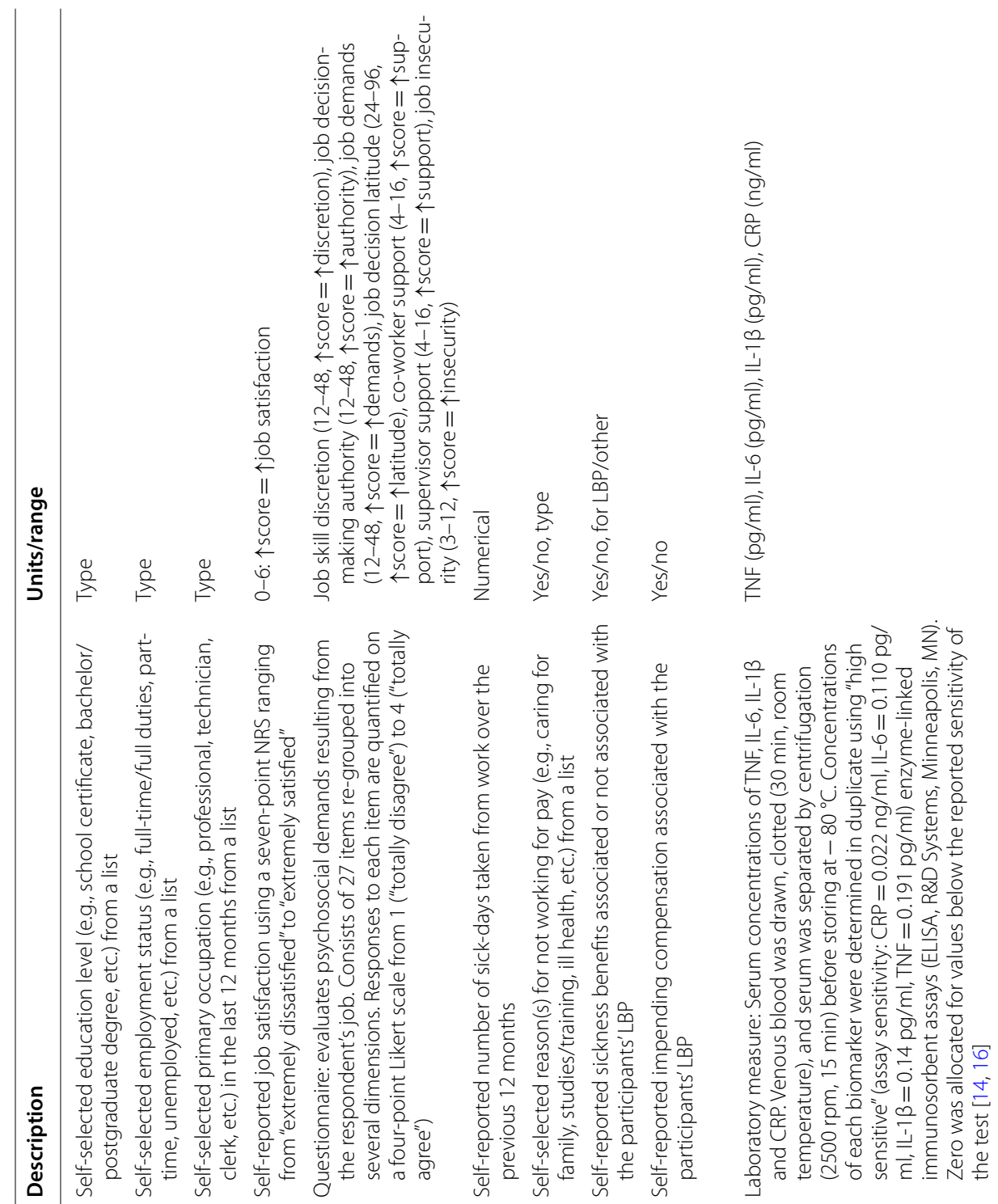

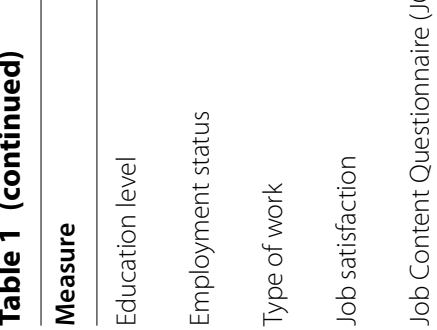

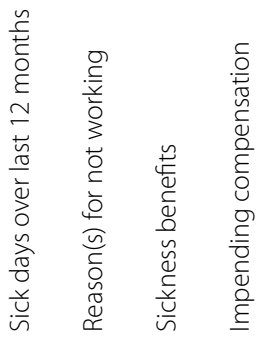

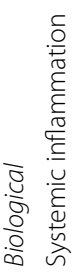




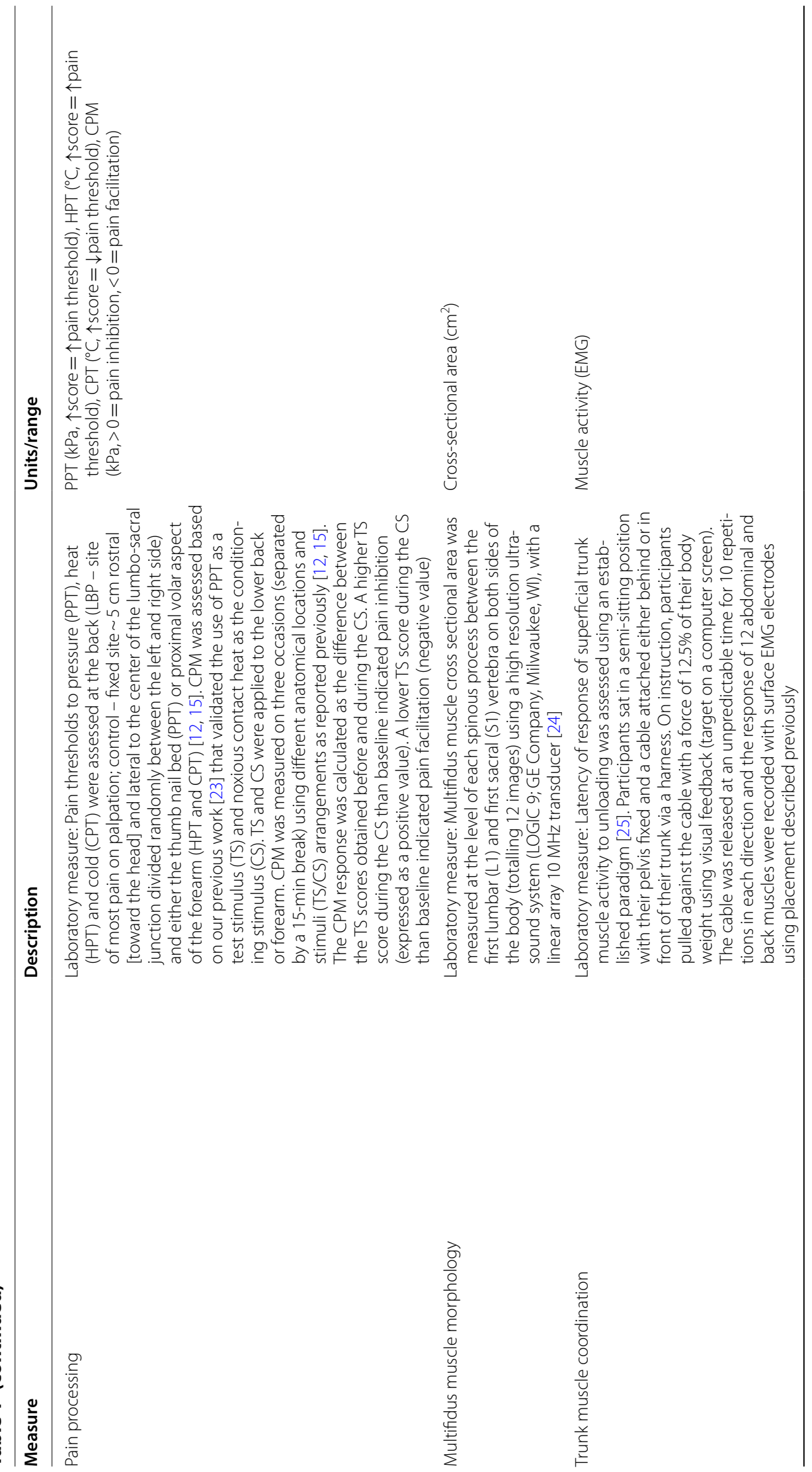




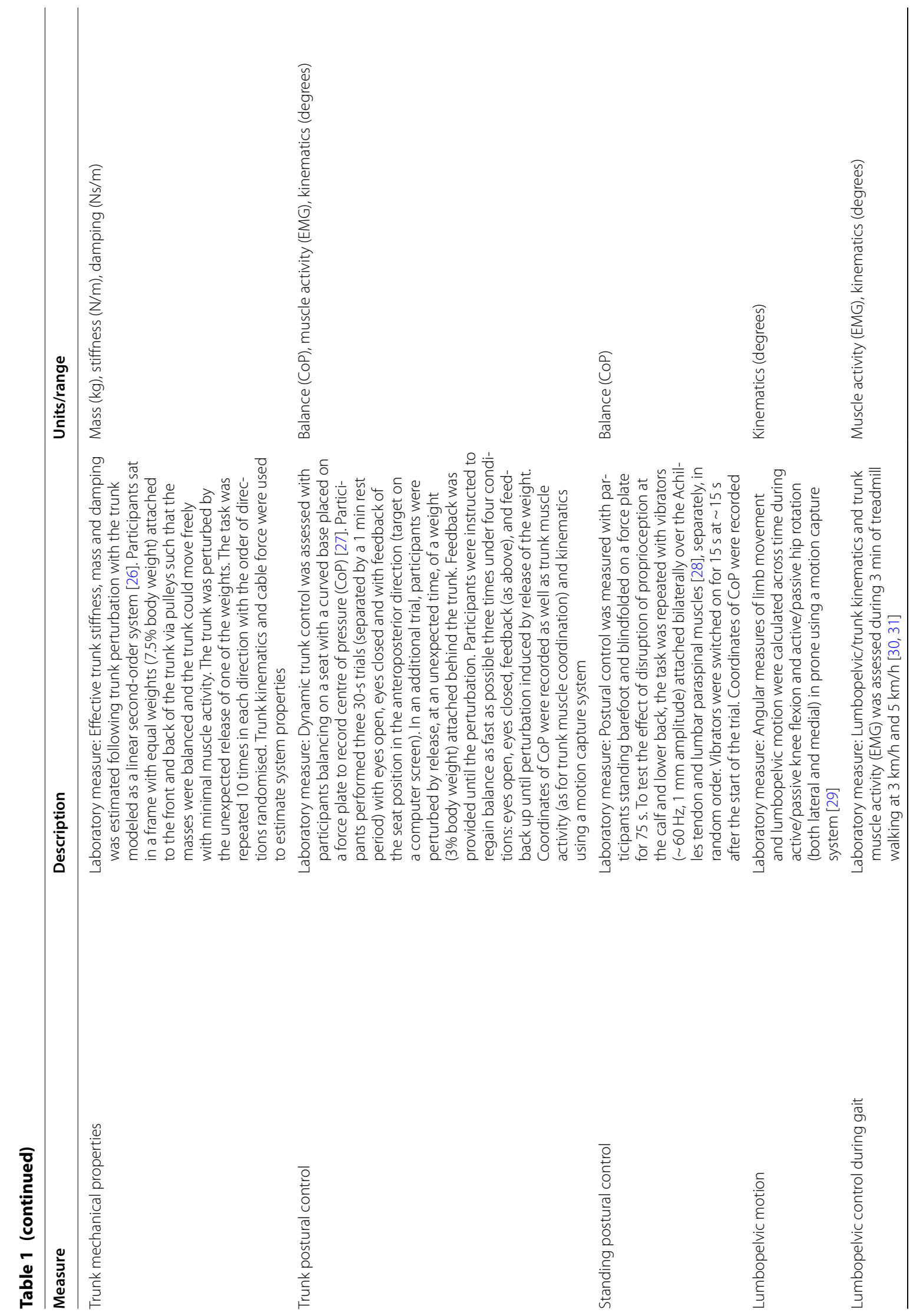




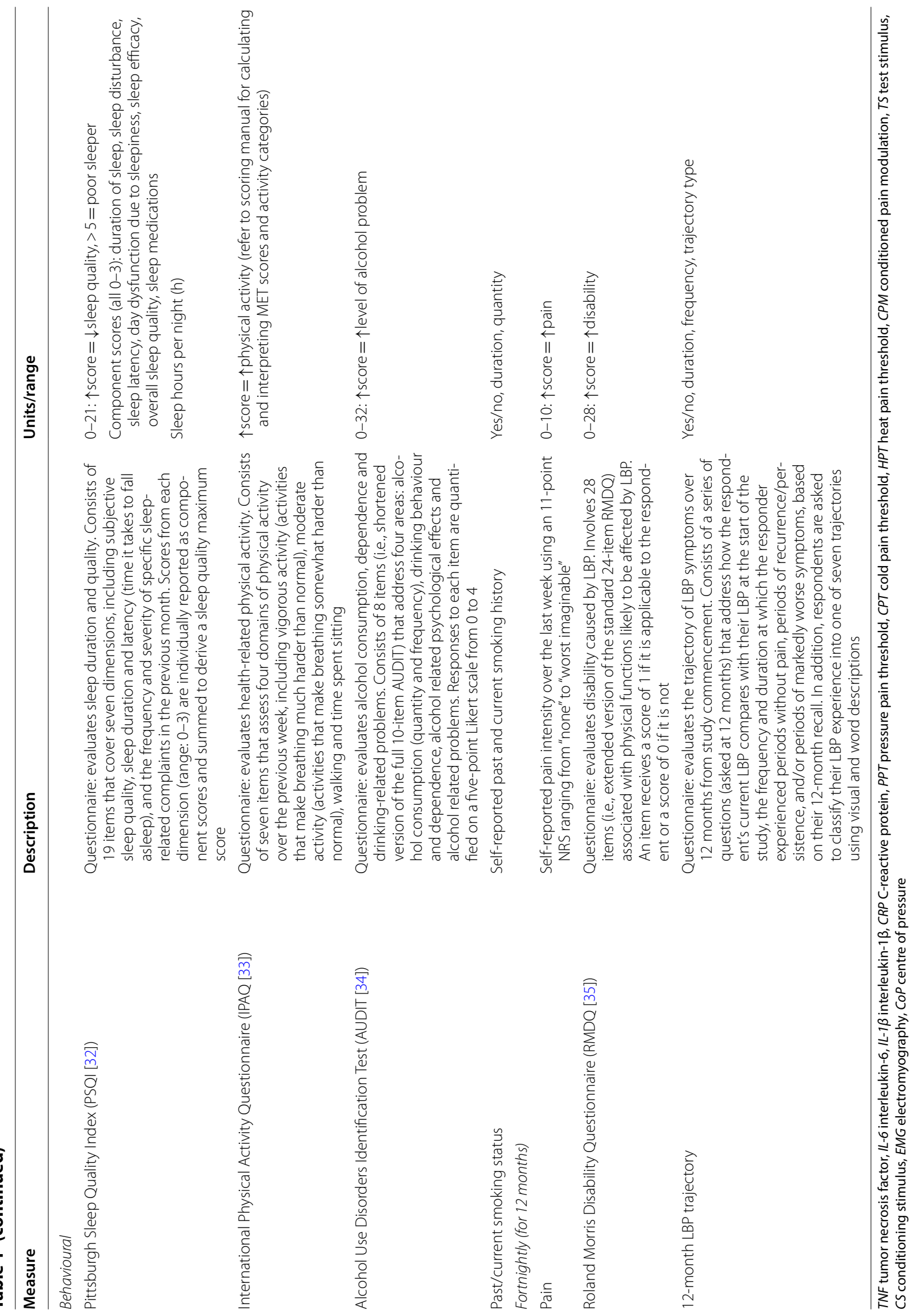




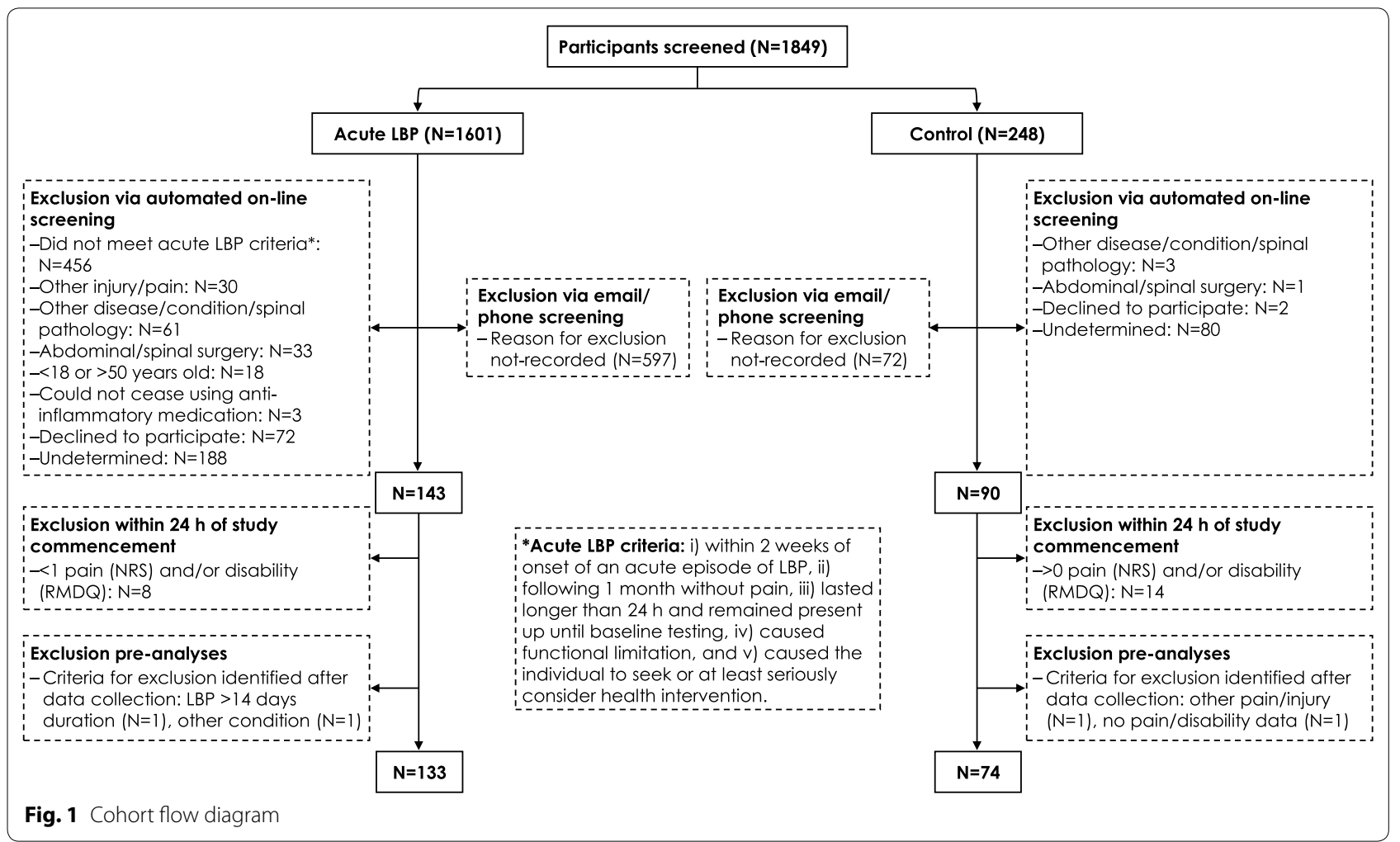

were identified for two participants with LBP (multiple sclerosis $[\mathrm{N}=1]$, duration of $\mathrm{LBP}>14$ days $[\mathrm{N}=1]$ ) and two control participants (no pain/disability data $[\mathrm{N}=1]$, pain/injury in another body region $[\mathrm{N}=1]$ ). These participants were excluded from the dataset. The final cohort included 133 and 74 participants in the LBP and control groups, respectively, for analyses.

\section{Measurements}

Details of the measures and at what time-point(s) they were implemented are presented in Table 1 and Additional file 1: Table S1. All variables were measured in a standardised order for each participant. Biological measures were those we considered to be the most promising candidate factors for predicting LBP recurrence/persistence based on previous research and plausible rationales founded on clinical, epidemiological and fundamental research. For psychological measures, we considered three key domains of relevance in LBP: cognitive (expectations, beliefs, and perceptions concerning pain) $[6,36-$ 38], emotional (distress, anxiety, and depression) [5], and behavioural (coping, pain behaviour, and activity/activity avoidance) [6,36,37]. Social measures were selected based on the Multinational Musculoskeletal Inception Cohort Study (MMICS) guidelines [39]. These guidelines were developed by an international expert team with review of the best available evidence from systematic/ narrative reviews and expert consensus. As it was not our intention to withhold treatment over the study period, we collected information regarding health care and medication use so that treatment variables can be included as covariates. The total number of variables was restricted to limit the required participant sample size, minimise the potential for over-fitting, and for cost-benefit.

\section{Sample size}

A sample size of 217 was calculated based on power to detect predictor variables using complex multiple regression models (i.e., 28 predictor variables, 5 a priori selected interactions) and growth curve modelling methods, while allowing for loss to follow-up. The planned sample size was not achieved due to feasibility issues as outlined in the "limitations" section. Although the achieved sample size $(\mathrm{N}=133)$ limits the ability to examine numerous interactions simultaneously, reduced model sizes and alternative methods (e.g., cluster analysis) have been applied successfully on data from this cohort [12-16].

\section{Data analysis}

All questionnaire-based measures (that could be quantitatively analysed) at baseline were compared between: (1) 
LBP and control participants, and (2) LBP participants who did and did not follow-up at 3, 6, 9 and 12 months.

\section{Results \\ Participant characteristics at baseline}

The characteristics of the study participants are described in Additional file 1: Table S4. Compared to controls, LBP participants were/had: taller and heavier, a higher BMI, a higher prevalence of comorbidities, a higher incidence of previous LBP, higher depressive and pain catastrophizing symptoms, higher self-reported job demands, more sick days (over the last 12 months), poorer sleep quality, more likely to have a history of cigarette smoking, and more likely to have performed vigorous physical activity on less days in the previous week.

\section{Participant attrition}

Of the 133 eligible acute LBP participants who were enrolled in the study and provided baseline data, 35 (26\%) were lost to follow-up for their laboratory-based measures (i.e., did not attempt/complete any biological measures) at 3 months, a further 9 at 6 months (total lost to follow-up $=44,33 \%$ ), and a further 5 at 9 months (total lost to follow-up $=49,37 \%$ ). As biological measures were not performed at 12 months, all participants were invited to complete the standard 3-montly questionnaire in addition to a separate recall questionnaire at 12 months, irrespective of whether or not they had continued or dropped out earlier. One or both of these were fully/partly completed by all but 41 of the 133 LBP participants who started the study (follow-up at 12 months: $\mathrm{N}=92$ ). For participants that did follow-up, Additional file 1: Table S5 shows the number of those that provided valid data for each of the 3-monthly questionnaire-based measures at each respective time-point. Ten control participants did not return for follow-up at 3 months. With respect to the completion rate of fortnightly pain (NRS) and disability (RMDQ) questionnaires, 85\% (1505 of 1770) were completed by LBP participants who were retained for follow-up (i.e., up to $3,6,9$ or 12 months) within 7 days of each questionnaire being issued, and 91\% (282 of 310) were completed by control participants (i.e., up to 3 months).

\section{Comparison of follow-up and non-follow-up participants}

Comparison of baseline characteristics between LBP participants who did and did not follow-up for laboratorybased measures at 3, 6 and 9 months, and questionnaire measures at 12 months, revealed some differences, as shown in Table 2.

\section{Discussion}

This paper profiles the only acute LBP cohort in which detailed biological, psychological, social and behavioural factors have been longitudinally and frequently collected, to date. The cohort has great potential to provide unique insight into the features that may predict and/or mediate long-term outcome [40].

The findings of baseline (acute LBP) characteristics presented here provide a foundation for future longitudinal analyses. Whether the findings can be generalised to a larger or clinical sample of individuals with early-acute LBP requires further and detailed studies of the condition during the early-acute phase. Despite the rate of loss to follow-up, most occurred after the first session, and baseline characteristics were generally similar between those who did and not return for follow-up.

Initial analyses of this cohort have revealed specific immune and nervous system features associated with the transition to persistent/recurrent LBP, and that various psychological and behavioural factors shape these relationships [12-16]. Ongoing analyses focus on elucidating the role of trunk neuromuscular, kinematic, mechanical and morphological properties, along with their possible interactions with psychosocial/behavioural features, in predicting LBP outcome.

\section{Limitations}

- The strict "acute LBP" inclusion criteria (i.e., within 2 weeks of onset of a LBP episode following 1 month without pain) rendered recruitment challenging $->50 \%$ of screened individuals did not meet these criteria.

- Study measures and follow-up procedures imposed substantial burden and explains the reported attrition.

- Missing data due to attrition was high as is usual in longitudinal cohorts, and statistical approaches (e.g., mixed effects models) have been, and will continue to be, used to minimise bias.

- The smaller than expected sample size limits the types of analyses to investigate interactions, and their interpretation; however, approaches such as cluster analyses have so far provided valuable insights.

- It was not possible to collect blood samples at a standardised time during the day for each participant at each time-point. To account for the diurnal variations in cytokines [41], time of blood collection was recorded for inclusion as a potential confounder when interpreting cytokine levels. 


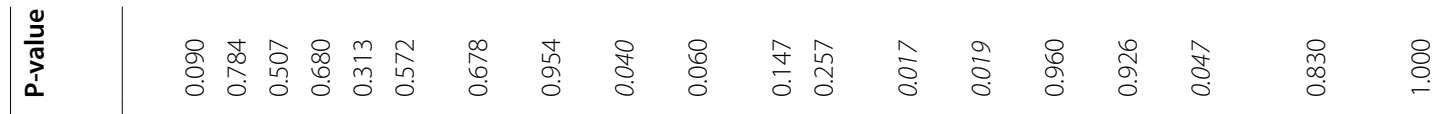

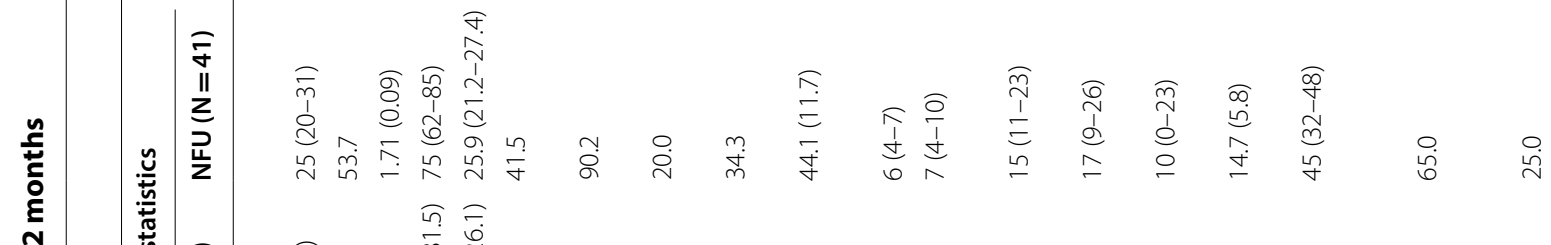

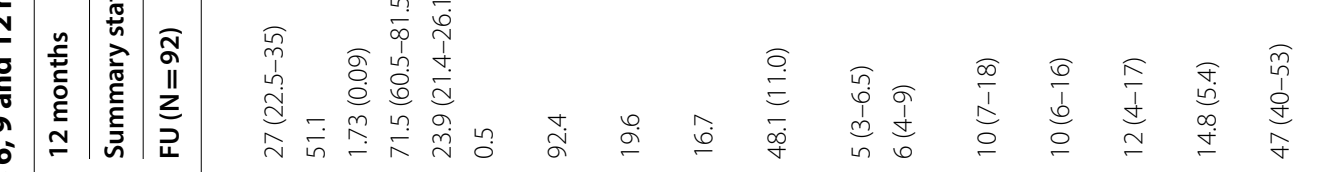

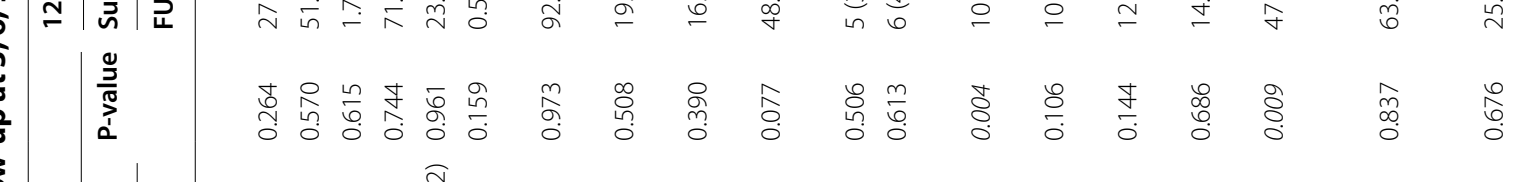

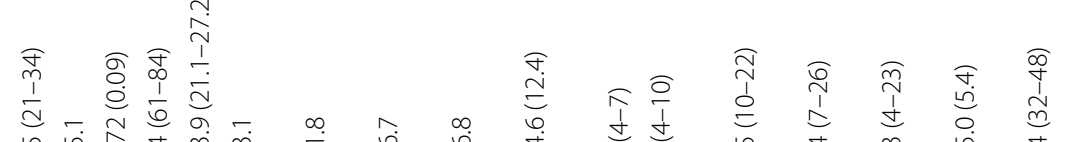

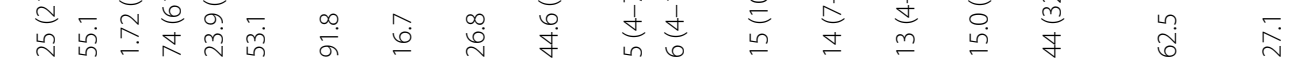

布 $\quad \underset{\substack{n \\ 0}}{\substack{0 \\ 0}}$

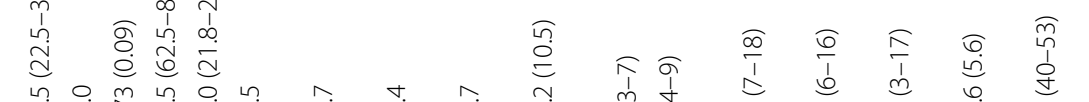

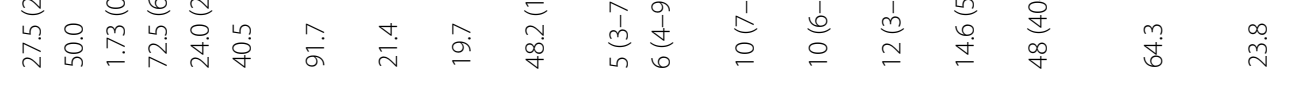

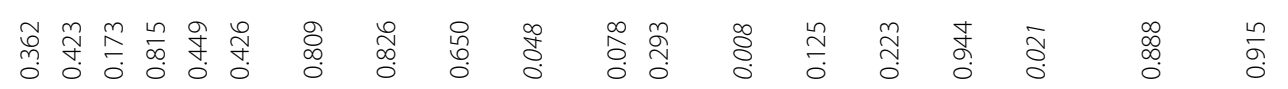
तn $\bar{n}$

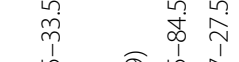

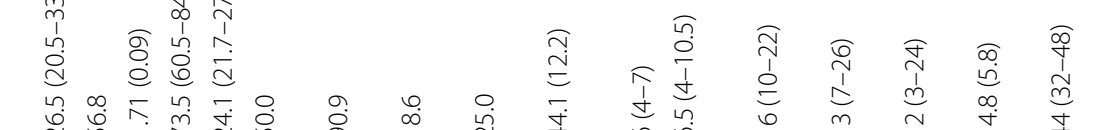

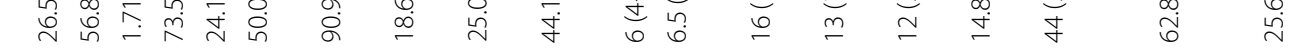

(1)

\section{(1)}




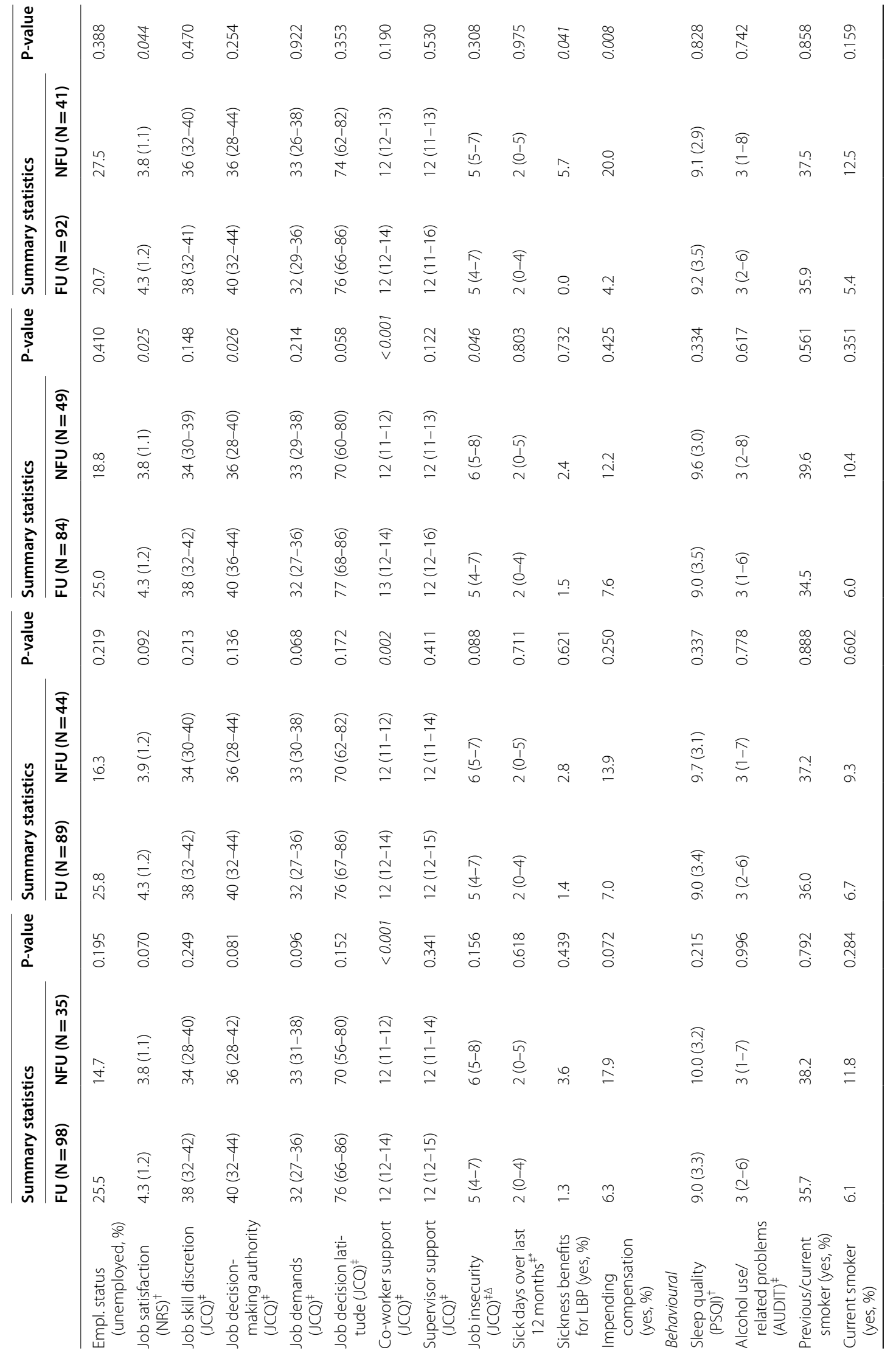




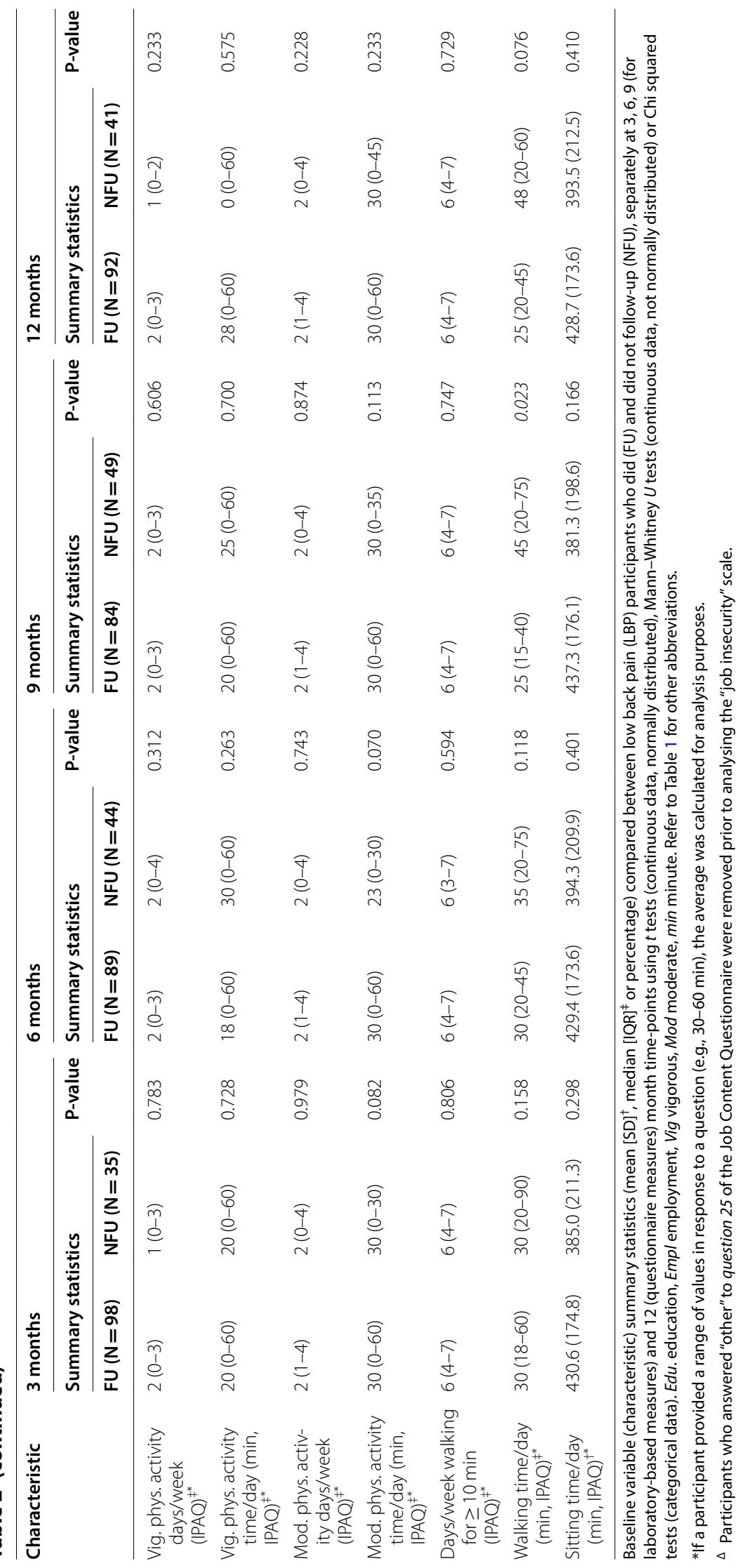




\section{Supplementary information}

Supplementary information accompanies this paper at https://doi. org/10.1186/s13104-020-05356-z.

Additional file 1. Additional Tables.

\begin{abstract}
Abbreviations
AUDIT: Alcohol Use Disorders Identification Test; BMI: Body mass index; CES-D: Centre for Epidemiological Studies of Depression Scale; CoP: Centre of pressure; CPM: Conditioned pain modulation; CPT: Cold pain threshold; CRP: C-reactive protein; CS: Conditioning stimulus; ELISA: Enzyme-linked immunosorbent assays; EMG: Electromyography; FABQ: Fear-Avoidance Beliefs Questionnaire; FU: Follow-up participants; HPT: Heat pain threshold; IPAQ: International Physical Activity Questionnaire; IQR: Interquartile range; JCQ: Job Content Questionnaire; IL-1ß: Interleukin-1B; IL-6: Interleukin-6; LBOS: LowBack Outcome Scale; LBP: Low back pain; NFU: Non-follow-up participants; NRS: Numerical rating scale; PCS: Pain Catastrophizing Scale; PPT: Pressure pain threshold; PSEQ: Pain Self-Efficacy Questionnaire; PSQI: Pittsburgh Sleep Quality Index; RMDQ: Roland Morris Disability Questionnaire; SD: Standard deviation; TNF: Tumor necrosis factor; TS: Test stimulus.
\end{abstract}

\section{Acknowledgements}

None.

\section{Authors' contribution}

Conceived and designed the study: DK, PH, WVDH, MB, JC, AK, LM, MN and MS. Recruitment of participants: DK, LO, RP and GR. Analysed the data: DK, $\mathrm{PH}, \mathrm{WVDH}$ and RM. Wrote the manuscript: DK and PH. All authors revised the manuscript. All authors read and approved the final manuscript.

\section{Funding}

This research was funded by the National Health and Medical Research Council (NHMRC) of Australia (Project Grant: ID631369; Program Grant: APP1091302). PWH supported by NHMRC Fellowship APP1 102905. GLM supported by NHMRC Fellowship ID1061279. MS supported by NHMRC Fellowship APP1002489. The funders had no role in the study design, data collection and analysis, decision to publish, or preparation of the manuscript.

\section{Availability of data and materials}

All data are held at The University of Queensland, Brisbane, Australia, and handled confidentially in a de-identified format. Currently, only the research team has access to the data. Proposals for collaborative analyses are invited to contact the lead author (Dr David Klyne: d.klyne@uq.edu.au) or principal investigator (Professor Paul Hodges: p.hodges@uq.edu.au).

\section{Ethics approval and consent to participate}

The study was approved by The University of Queensland's Human Research Ethics Committee (ID: 2010000045), Royal Brisbane \& Women's Hospital Human Research Ethics Committee (ID: HREC/13/QRBW/268), and the Uniting Care Health Human Research Ethics Committee (ID: 1404). All participants provided written informed consent, were informed of their right to withdraw from the study at any time without penalty, and were informed of the study purpose.

\section{Consent for publication}

Not applicable.

\section{Competing interests}

The authors declare that they have no competing interests.

\section{Author details}

${ }^{1}$ NHMRC Centre of Clinical Research Excellence in Spinal Pain, Injury and Health, School of Health and Rehabilitation Sciences, The University of Queensland, Brisbane, QLD 4072, Australia. ${ }^{2}$ Department of Anatomy and Cell Biology, Lewis Katz School of Medicine, Temple University, Philadelphia, USA. ${ }^{3}$ MSU Center for Orthopedic Research, Department of Osteopathic Surgical Specialties, Michigan State University, East Lansing, MI, USA. ${ }^{4}$ School of Health and Rehabilitation Sciences, The University of Queensland, Brisbane,
Australia. ${ }^{5}$ Department of Physiotherapy, LUNEX International University of Health, Exercise and Sports, Differdange, Luxembourg. ${ }^{6}$ IIMPACT, University of South Australia, Adelaide, Australia. ${ }^{7}$ Pain Management Research Institute, Royal North Shore Hospital, The University of Sydney, Sydney, Australia. ${ }^{8}$ NHMRC Centre of Research Excellence in Road Traffic Injury Recovery, The University of Queensland, Brisbane, Australia. ${ }^{9}$ Recover Injury Research Centre, The University of Queensland, Brisbane, Australia.

Received: 12 Auqust 2020 Accepted: 23 October 2020

Published online: 17 November 2020

\section{References}

1. Hoy D, March L, Brooks P, Blyth F, Woolf A, Bain C, et al. The global burden of low back pain: estimates from the Global Burden of Disease 2010 study. Ann RheumDis. 2014;73(6):968-74. https://doi.org/10.1136/annrh eumdis-2013-204428.

2. Dagenais S, Caro J, Haldeman S. A systematic review of low back pain cost of illness studies in the United States and internationally. Spine J. 2008;8(1):8-20. https://doi.org/10.1016/j.spinee.2007.10.005.

3. Pengel LHM, Herbert RD, Maher CG, Refshauge KM. Acute low back pain: systematic review of its prognosis. Brit Med J. 2003;327(7410):323-5. https ://doi.org/10.1136/bmj.327.7410.323.

4. Henschke N, Maher CG, Refshauge KM, Herbert RD, Cumming RG, Bleasel $J$, et al. Prognosis in patients with recent onset low back pain in Australian primary care: inception cohort study. Brit Med J. 2008a. https://doi. org/10.1136/bmj.a171.

5. Pincus T, Burton AK, Vogel S, Field AP. A systematic review of psychological factors as predictors of chronicity/disability in prospective cohorts of low back pain. Spine. 2002;1(27):109-20.

6. Linton SJ. A review of psychological risk factors in back and neck pain. Spine. 2000;25(9):1148-56.

7. Pincus T, Vogel S, Burton AK, Santos R, Field AP. Fear avoidance and prognosis in back pain: a systematic review and synthesis of current evidence. Arthritis Rheum. 2006;54(12):3999-4010. https://doi.org/10.1002/ art.22273.

8. Bieringsorensen F. Physical measurements as risk indicators for low-back trouble over a one-year period. Spine. 1984;9(2):106-19. https://doi. org/10.1097/00007632-198403000-00002.

9. Hamberg-van Reenen HH, Ariens GAM, Blatter BM, van Mechelen W, Bongers PM. A systematic review of the relation between physical capacity and future low back and neck/shoulder pain. Pain. 2007;130(1-2):93107. https://doi.org/10.1016/j.pain.2006.11.004

10. Airaksinen O, Brox Jl, Cedraschi C, Hildebrandt J, Klaber-Moffett J, Kovacs $F$, et al. Chapter 4. European guidelines for the management of chronic nonspecific low back pain. Eur Spine J. 2006;15(Suppl 2):192-300. https:// doi.org/10.1007/s00586-006-1072-1.

11 Deyo RA, Phillips WR. Low back pain A primary care challenge. Spine. 1996;21(24):2826-32. https://doi.org/10.1097/00007632-19961215000003.

12 Klyne DM, Moseley GL, Sterling M, Barbe MF, Hodges PW. Are Signs of central sensitization in acute low back pain a precursor to poor outcome? J Pain. 2019. https://doi.org/10.1016/j.jpain.2019.03.001.

13. Klyne DM, Hodges PW. Circulating adipokines in predicting the transition from acute to persistent low back pain. Pain Med. 2020. https://doi. org/10.1093/pm/pnaa052.

14. Klyne DM, Barbe MF, van den Hoorn W, Hodges PW. ISSLS PRIZE IN CLINICAL SCIENCE 2018: longitudinal analysis of inflammatory, psychological, and sleep-related factors following an acute low back pain episode-the good, the bad, and the ugly. Eur Spine J. 2018;27(4):763-77. https://doi. org/10.1007/s00586-018-5490-7.

15 Klyne DM, Moseley GL, Sterling M, Barbe MF, Hodges PW. Individual Variation in Pain Sensitivity and Conditioned Pain Modulation in Acute Low Back Pain: Effect of Stimulus Type, Sleep, and Psychological and Lifestyle Factors. J Pain. 2018;19(8):942e-1-e-18. https://doi.org/10.1016/j.jpain .2018.02.017

16. Klyne DM, Barbe MF, Hodges PW. Systemic inflammatory profiles and their relationships with demographic, behavioural and clinical features in acute low back pain. Brain Behav Immun. 2017;60:84-92. https://doi. org/10.1016/j.bbi.2016.10.003. 
17 Greenough CG, Fraser RD. Assessment of outcome in patients with lowback pain. Spine. 1992;17(1):36-41.

18. Radloff LS. The CES-D Scale: a new self-report depression scale for research in the general population. ApplPsycholMeas. 1977;1:385-401.

19. Osman A, Barrios FX, Kopper BA, Hauptmann W, Jones J, O'Neill E. Factor structure, reliability, and validity of the pain catastrophizing scale. J Behav Med. 1997;20(6):589-605. https://doi.org/10.1023/A:1025570508954.

20. Waddell G, Newton M, Henderson I, Somerville D, Main CJ. A Fear-Avoidance Beliefs Questionnaire (FABQ) and the role of fear-avoidance beliefs in chronic low back pain and disability. Pain. 1993;52(2):157-68.

21. Nicholas MK. The pain self-efficacy questionnaire: taking pain into account. Eur J Pain. 2007;11(2):153-63. https://doi.org/10.1016/j.ejpai n.2005.12.008.

22. Karasek R, Brisson C, Kawakami N, Houtman I, Bongers P, Amick B. The Job Content Questionnaire (JCQ): an instrument for internationally comparative assessments of psychosocial job characteristics. J Occup Health Psychol. 1998;3(4):322-55.

23 Klyne DM, Schmid AB, Moseley GL, Sterling M, Hodges PW. Effect of types and anatomic arrangement of painful stimuli on conditioned pain modulation. J Pain. 2015;16(2):176-85. https://doi.org/10.1016/j.jpain .2014.11.005.

24 Stokes M, Hides J, Elliott J, Kiesel K, Hodges P. Rehabilitative ultrasound imaging of the posterior paraspinal muscles. J Orthop Sports Phys Ther. 2007;37(10):581-95. https://doi.org/10.2519/jospt.2007.2599.

25 Cholewicki J, Silfies SP, Shah RA, Greene HS, Reeves NP, Alvi K, et al. Delayed trunk muscle reflex responses increase the risk of low back injuries. Spine. 2005;30(23):2614-20.

26 Hodges P, van den Hoorn W, Dawson A, Cholewicki J. Changes in the mechanical properties of the trunk in low back pain may be associated with recurrence. J Biomech. 2009;42(1):61-6. https://doi.org/10.1016/j. jbiomech.2008.10.001.

27 van Dieen JH, Koppes LL, Twisk JW. Low back pain history and postural sway in unstable sitting. Spine. 2010;35(7):812-7. https://doi.org/10.1097/ BRS.0b013e3181bb81a8.

28 Brumagne S, Cordo P, Lysens R, Verschueren S, Swinnen S. The role of paraspinal muscle spindles in lumbosacral position sense in individuals with and without low back pain. Spine. 2000;25(8):989-94. https://doi. org/10.1097/00007632-200004150-00015.

29 Scholtes SA, Gombatto SP, Van Dillen LR. Differences in lumbopelvic motion between people with and people without low back pain during two lower limb movement tests. ClinBiomech. 2009;24(1):7-12. https:// doi.org/10.1016/j.clinbiomech.2008.09.008.

30 Bruijn SM, Meijer OG, van Dieen JH, Kingma I, Lamoth CJ. Coordination of leg swing, thorax rotations, and pelvis rotations during gait: the organisation of total body angular momentum. Gait Posture. 2008;27(3):455-62. https://doi.org/10.1016/j.gaitpost.2007.05.017.

31 Lamoth CJ, Meijer OG, Wuisman PI, van Dieen JH, Levin MF, Beek PJ. Pelvis-thorax coordination in the transverse plane during walking in persons with nonspecific low back pain. Spine. 2002;27(4):E92-9. https:// doi.org/10.1097/00007632-200202150-00016.

32. Buysse DJ, Reynolds CF, Monk TH, Berman SR, Kupfer DJ. The Pittsburgh Sleep Quality Index: a new instrument for psychiatric practice and research. Psychiat Res. 1989;28(2):193-213. https://doi.org/10.1016/01651781(89)90047-4.

33 Lee PH, Macfarlane DJ, Lam TH, Stewart SM. Validity of the International Physical Activity Questionnaire Short Form (IPAQ-SF): a systematic review. Int J BehavNutr Phys Act. 2011;8:115. https://doi. org/10.1186/1479-5868-8-115.

34. Babor TF, Higgins-Biddle J, Saunders JB, Monteiro MG. AUDIT: The Alcohol Use Disorders Identification Test: guidelines for use in primary care. Geneva: World Health Organization; 2001.

35 Roland M, Morris R. A study of the natural history of back pain. Part I: development of a reliable and sensitive measure of disability in low-back pain. Spine. 1983;8(2):141-4.

36. Mallen CD, Peat G, Thomas E, Dunn KM, Croft PR. Prognostic factors for musculoskeletal pain in primary care: a systematic review. Brit J Gen Pract. 2007;57(541):655-61.

37. Henschke N, Maher CG, Refshauge KM, Herbert RD, Cumming RG, Bleasel J, et al. Prognosis in patients with recent onset low back pain in Australian primary care: inception cohort study. BMJ. 2008b;337:a171. https://doi. org/10.1136/bmj.a171.

38. Boersma K, Linton SJ. How does persistent pain develop? An analysis of the relationship between psychological variables, pain and function across stages of chronicity. Behav Res Ther. 2005;43(11):1495-507. https:// doi.org/10.1016/j.brat.2004.11.006.

39 Pincus T, Santos R, Breen A, Burton AK, Underwood M, Multinational Musculoskeletal Inception Cohort Study C. A review and proposal for a core set of factors for prospective cohorts in low back pain: a consensus statement. Arthritis Rheum. 2008;59(1):14-24. https://doi.org/10.1002/ art.23251.

40 Klyne DM, Hodges PW. Letter to the editor concerning "Multiple confounders influence the association between low-grade systemic inflammation and musculoskeletal pain. A call for a prudent interpretation of the literature" by Schipholt et al. Spine J. 2019;19(11):1899-900. https:// doi.org/10.1016/j.spinee.2019.06.011.

41. Petrovsky N, MCNair P, Harrison LC. Diurnal rhythms of pro-inflammatory cytokines: regulation by plasma cortisol and therapeutic implications. Cytokine. 1998;10(4):307-12. https://doi.org/10.1006/cyto.1997.0289.

\section{Publisher's Note}

Springer Nature remains neutral with regard to jurisdictional claims in published maps and institutional affiliations.

Ready to submit your research? Choose BMC and benefit from

- fast, convenient online submission

- thorough peer review by experienced researchers in your field

- rapid publication on acceptance

- support for research data, including large and complex data types

- gold Open Access which fosters wider collaboration and increased citations

- maximum visibility for your research: over 100M website views per year

At BMC, research is always in progress.

Learn more biomedcentral.com/submissions 